\title{
An electronic social space for consultation and collaboration.
}

\author{
S. Qureshi
}

EURIDIS, Erasmus University Rotterdam

Burg. Oudlaan 50, P.O. Box 1738

3000 DR Rotterdam, The Netherlands

Tel: +3110 408 2287, Fax: +31104526134

Email: squreshi@fac.fbk.eur.nl,orqureshi@clus1.ulcc.ac.uk

\begin{abstract}
This paper describes the use of a distributed group communication system to support consultation and collaboration among people in different international agencies who cannot meet face to face. Following a description of the network of international agencies and the technology that they use, two types of interaction are presented. The study culminates with an analysis which provides practical insights into the type of support required for a globally networked way of working.
\end{abstract}

\section{Keywords}

Social space, electronic social space, appropriation, adaptation

\section{INTRODUCTION}

Group processes have been identified as being one of the main factors contributing to the development of networks in the work place. Kanter (1983) refers to group processes as integrating devices that enable the organisation to maintain a degree of cohesion among its many dispersed departments. Electronic support for facilitating group processes has arisen as a response to the need to support problem solving processes not only in face to face meetings but also among a group of geographically dispersed individuals who cannot meet physically. This latter form of communication is seen to support a network form and is the subject of this paper.

Group Support Systems (GSS) are more frequently applied to structure face to face meetings. Ideas and comments generated by the participants in the electronic group meetings appear together on one screen without the identity or the source of the comments ever being disclosed (as in the case of 
GroupSystems V). GSS have been useful in providing anonymity to the members' comments in a face to face discussion, and facilitating the problem solving process. Proponents of GSS argue that the outcome of these meetings result in better quality decisions (Dennis et al 1988, Nunamaker et al 1988). Although there has been much research into the areas in which GSS may be effectively used, authors such as DeSanctis and Gallupe (1987) and Perin (1991), state that there are situations in which GSS technology, especially in its current state, may not help. For example, simple tasks requiring two or three people may be accomplished more effectively in a regular setting. This suggests that the technology alone cannot ensure that distributed group meetings are effective and efficient.

There is a sense that the support of work processes in which people do not physically meet or see each other may be provided within 'virtual structures' through Computer Mediated Communications Systems (CMCS). As defined by Hiltz and Turoff (1992), these systems use computers and telecommunications networks to store, deliver, regulate and process communication among the group members and between the computer and the group. Although the most common form of CMCS is electronic mail, other computerised conferencing and bulletin board software is classified under this heading. This medium of communication has been supporting very large scientific and professional communities. In the context of a network form in which there is a need to coordinate geographically dispersed activities on a regular basis, the existence of networking is increasingly being seen as a necessity (Charan 1991, Drucker 1988, Keisler et al 1987).

This paper describes the use of an electronic communication system to support communication between a group of people from different international agencies. A brief description is provided of an international agency network which is seen to evolve a network way of working and requires electronic support for consultation and collaboration. An electronic communication system that provides this support is introduced and two ways in which it is used to support the meetings are described. Insights from this description are distilled using an interpretivist research strategy into practical conclusions on how the technology may best support consultation and collaboration between a geographically distributed group of people in different organisations.

\section{RESEARCH APPROACH}

The approach of this research follows an interpretivist strategy using a single case study. An interpretivist research strategy enables communication relations to be considered in their natural setting. As research into human networking is still in its formative stages, the use of a case study is valuable in that a real world situation is described in great depth. The case study is not used in this research to validate a theory or hypothesis but it is used to generate conceptual insights which may apply to other situations. In remaining consistent with an interpretivist research strategy, an international agency network is examined in its natural setting (the electronic notice board) as a case study and the researcher is part of the phenomena being investigated. A justification of this approach is provided in greater detail in Qureshi (1995).

When investigating electronic meetings it is useful to consider social structures. The structuration perspective proposes an emergent view, in that there are deep structures of power, and influence which constrain human action and the patterns of relations that emerge. At the same time human action helps to shape and define social structure (Giddens 1984). The analysis of this paper employs a structuration perspective and builds upon Linda Harasim's term, social space to describe the way in which human communication has transformed computer networks into what she calls 'places' where people 'connect' with each other. This research takes the notion of the social space as described by Harasim (1993) a step further by considering the social processes that affect interaction on the electronic medium of communication. It recognises that the technology may have an affect on the social processes and thus the 
patterns of relations and behaviours that emerge. Hence the term, electronic social space, is used to describe the environment in which the network phenomena are investigated. This notion of the creation of social structure on the electronic medium of communication provides us with a basis upon which to tackle the vaguer more complex aspects of human interaction which are nonetheless significant components of a network way of working.

\section{A NETWORK OF INTERNATIONAL AGENCIES}

The Informal Consultative Group of Information Technology for Development (ICGITD) was proposed at a collaborative meeting called "Information Technology for Development: Informal Consultation for Mobilising Resources" co-hosted by the Commonwealth Secretariat and the International Development Research Centre (IDRC) in London from the 26th to the 28th of January 1993. It comprised representatives from all the major and key agencies active in the field of IT for development. At the time, the ICGITD included the following international and donor agencies: the Canadian International Development Agency (CIDA), Commission of the European Communities (CEC DGXII), Danish International Development Agency (DANIDA), International Development Research Centre (IDRC), International Conference for Computer Communication (ICCC), United Nations University (UNU), United Nations Development Programme (UNDP), United Nations Educational, Social and Cultural Organisation (UNESCO), USAID Centre for Development, World Bank, and the African (ADB) and Caribbean Development (CDB) Banks. The ICGITD consisted of people representing a set of donor agencies who wanted to be able to exchange ideas and experiences on information technology projects in developing countries.

The purpose as set out in the agenda of the Conference, was to "allow informal dialogue to be extended in order to facilitate collaboration". It was agreed that "identified officials from a diverse range of agencies, including many of those represented at the meeting, could share concerns, opportunities, and outline project proposals on a strictly "off-the-record" basis. The issues raised could be confidential and sensitive, and yet required a degree of open discussion and debate. Project information, ideas and experiences, joint funding initiatives, and publications were the main areas requiring consultation among members of the group. The intention was to encourage brainstorming and an active exchange of ideas to ensure informed and thus effective collaboration in projects.

\subsection{The mechanism}

A mechanism for consultation and collaboration was put in place to enable the members of the ICGITD to communicate on a regular basis with respect to their initiatives in the developing world. The primary objectives of this mechanism as proposed at the collaborative meeting in January 1993, were:

"Methods and criteria for identifying appropriate officials within key agencies.

Electronic mechanisms for rapid sharing of proposals and developments.

Suggestions regarding procedural mechanisms for sharing information without implications of formal agency commitment - through the Journal of IT for Development."

An electronic mechanism for meeting and consultation was agreed upon in which the members of this group were able to communicate electronically. The intention was to: 


\section{"Facilitate the operation of the software and enabling the registration of ICGITD members.}

Provide training support and documentation for those using this facility.

Moderate the discussions to ensure that members are able to share their views and at the same time allow other members to do so. Ideas and views generated by these sessions are then compiled and distributed to those involved."

In response to the above, an electronic communication system was made available to all the ICGITD members and was used to encourage confidential electronic discussion. It was enhanced to accommodate the needs of the ICGITD members. The result of this development work was an asynchronous capability for structuring discussions, and a synchronous talk facility allowing electronic meetings to take place at the same time among people situated in different parts of the world. Technical considerations such as confidentiality and privacy meant that other users were not given access to information generated by ICGITD users.

\section{THE DISTRIBUTED GROUP COMMUNICATION TECHNOLOGY}

The technology used to support the ICGITD is a bulletin board facility known as The Notice Board which runs on an internet machine at the University of London Computer Centre and has been developed at the City University Computer Support Centre. The Notice Board has been designed to suit the requirements of the ICGITD. It is a closed system, operating on a high security machine, which provides confidentiality and at the same time accessibility to a wide range of participants who connect to it from different parts of the world. In order to be able to access the Notice Board, ICGITD members must have an account on the ULCC machine. This entails a process of registration afterwhich members receive documentation and support for using the facility.

The Notice Board enables essentially two types of communication to take place. Using the classification of DeSanctis and Gallupe (1987), it enables different time different place communication through the discussion board facility. While its functionality is similar to that provided by Vax Notes, the discussion board is more user friendly in that it enables participants to air their views relating to certain topics of discussion by automatically creating *menus and files. On the ICGITD discussion board, participants may enter comments on a particular topic within a file in which the different contributions are marked with the names of their respective authors. Within this discussion board facility, comments may be grouped into a tree structure in which different topics may be pointers to a set of topics or they may include files containing comments. This facility is intended to enable participants to structure and organise their contributions.

The second type of communication enabled by the Notice Board is same time different place communication which is available through the talker. The talk facility on the notice board, similar in functionality to the internet IRC, allows participants from different parts of the world to communicate with each other synchronously (at the same time). The communication is not anonymous, and comments typed by each participant are displayed next to their name on the virtual space. Communicating on the talker enables meetings to be held without having to move the participants away from their offices or their countries. In the course of these synchronous meetings, the talker also enables private conversations to take place in virtual rooms. Participants may go into one of these virtual rooms, invite other selected 
participants and once the invited participants enter the private room, the room can be locked to restrict others from joining in the private conversation.

\subsection{Supporting consultation and collaboration}

The technology alone cannot be seen to support the network. Preparation well in advance of the meetings is essential to ensure that the time people spend in the electronic meetings is fruitful. The purpose of the meetings has to be clear in the minds of the participants. For the purpose of the ICGITD, the discussion board facility is used to make announcements of forthcoming projects and workshops, and the talker is used to follow up issues with interactive meetings.

\section{Selection of target group}

At the first instance, it is important to be clear about who is going to attend these sessions and for what purpose. The nature and importance of a particular consultation exercise has to be established properly. In the case of the ICGITD this process is carried out outside of the electronic communication system as much of this is based on the institutional pressures that govern the nature and function of the network. It has been the experience of the authors that it takes a few weeks for people to coordinate their agendas and sort out any technical or connectivity problems that may arise.

\section{Definition of items to be discussed}

Once a group of participants have confirmed intent to have a meeting, it is necessary to proceed with defining an agenda. This agenda is then sent to all the participants for feedback and further modification if necessary. This establishes the nature and importance of meetings to participants. Agenda items do not have to be volumes of text, but well thought out simple easy to understand points that participants can identify with. These are posted on the discussion board facility and emailed to the participants well in advance of when the meeting is scheduled to take place especially where a group may have a low level of cohesion.

\section{Conducting electronic discussions}

The role of the chairperson is important when conducting an electronic discussion. For professional meetings conducted electronically in real time (same time, different place), it is customary to appoint a facilitator who is conversant in the topics being discussed and is familiar with the technology. The role of the facilitator is to guide the participants through the discussions drawing upon the capabilities of the technology. Electronic meetings that are conducted asynchronously (different place, different time), need to be moderated so that key issues are highlighted and superfluous comments are removed from the system. The role of the chairperson in the distributed electronic meetings appears to be a dominant one, where there is pressure to ensure effective discussion and participation, and to focus on key issues. 


\subsection{Structuring discussions}

The ability to structure information is a notable feature of the discussion board facility. The generation and evaluation of ideas takes place on the discussion board facility as it enables topics of discussion to be organised and potentially evaluated. These discussions are asynchronous and require moderation in that superfluous or repetitive comments need to be removed and important comments

placed within appropriate headings. This means that users have to make a choice early on in the presentation of their points on how to structure their ideas on the discussion board. The first level of the ICGITD discussions as illustrated in Figure 1, are composed of four main topics: The topic Impacts is a file and the other three are menu items. The first topic, Impacts, is entered as a file (there is an Add written next to it) and can be accessed by pressing $I$ on the keyboard. A portion of the discussion file containing comments from different participants is illustrated in Figure 2.

In this file, participants add their comments for discussion or respond to existing comments on the file by either sending private messages to the author of a comment or by adding additional comments to this file. The Impacts file provides the capability for idea generation on a particular topic. Although a certain amount of brainstorming may have occurred in the file, it is not possible to evaluate the topic as the nature of the discussion on a file is more fluid and less structured than a discussion that may have been taking place under menu items.

An illustration of the way in which structured discussions take place using menu items is provided by the topic, IT Policy; this is a menu item comprising two topics created as files. As illustrated in Figure 3, the two topics being discussed are: IT Policy in Africa, and Is there is a need ? In this way a particular topic may be broken down to into separate menu items of discussion files. The $\mathbf{R}$ option in the ICGITD discussion board reveals a deeper menu structure. This aspect of the discussion board is concerned with posting material on the various 'Projects' with an underlying purpose of seeking 
collaboration on projects. As is illustrated in Figure 4, it displays a structure that reflects the need for more concrete outcomes. We find that an three areas being discussed under 'Projects', are menu items and hence give rise to deeper levels of topics. If we consider 'Pipeline Projects' (the P option) we find that there are two topics upon which the discussion has focused: 'Equipment' and 'Training' (both of which are files) and are illustrated in Figure 5.

There are no voting tools available on the discussion board. As the discussion board is not used take decisions yet, the need for voting tools has not been expressed. However, voting does take place in the face to face meetings which suggests that this technology is more suitable for exchanging information and ideas for consultation rather than for decision making. At the same time, the discussion board does enable certain areas for collaboration to be identified as a large amount of information may be pos

The value of this form of communication to the ICGITD appears to be in the ability to raise issues, exchange information and ideas in order to achieve some sort of understanding of the situation. The final purpose is to be able to identify certain areas for collaboration and build working relations based on this joint understanding. In comparison, Dennis $e t$ al 1988 and Nunamaker et al 1988 have demonstrated that the use of group

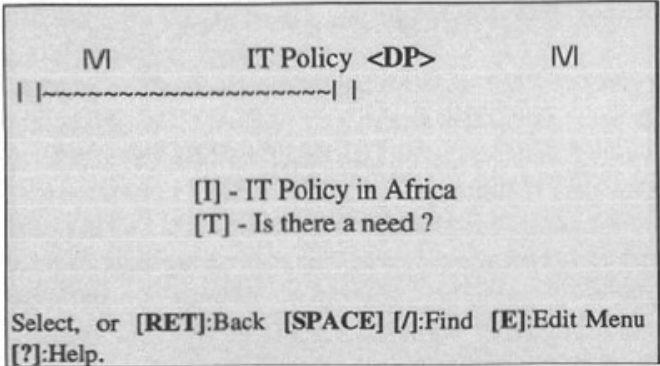

Figure 3 The ICGITD Discussion Board: IT Policy.

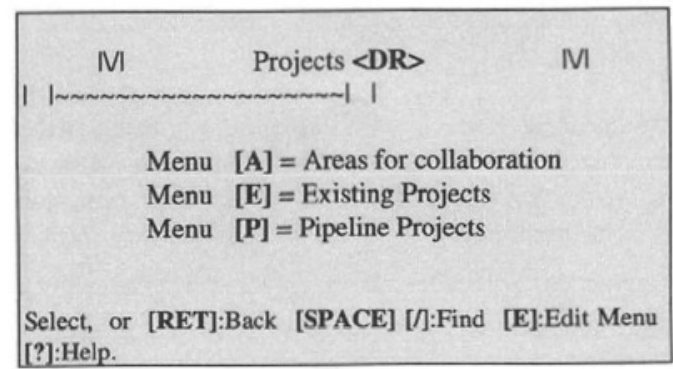

Figure 4 The ICGITD Discussion Board: Projects.

osted on it for participants to scrutinise at their own leisure.

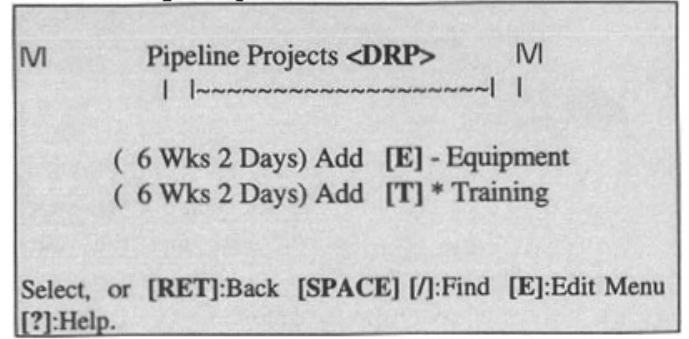

Figure 5 Projects: Pipeline Projects. support systems have supported problem solving processes and have brought about better quality of decisions.

In summary, the discussion board provides a means of exchanging information and ideas while at the same focusing on certain topics. It is not conducive however, to enabling participants to take certain topics further into meetings, brainstorming sessions and/or debates. This requirement is addressed by the synchronous talker described in the following section. 


\subsection{Conducting meetings}

The synchronous talker provides a different mode of interaction than the discussion board. Electronic meetings held using a talk facility can support up to 450 people at any one time, but a productive meeting has between 5 and 7 people. The talker enables participants to communicate within their own rooms in which they may invite people from the default common room to engage in private conversation. While these rooms are used in trial sessions, the main ICGITD meetings take place in the virtual common room on the talker. In this, the talker facilitates brainstorming on specific issues and enables focus to be achieved on specific areas requiring decisions to be made or further discussion to be carried out. This form of synchronous computer conferencing is seen by the consultative group to be useful as long as there are some clearly defined objectives. As stated by a participant of an electronic ICGITD meeting:

"Our experience with computer conferencing ..... is that the more clearly defined the objectives of the exercise and the topic of the problem being discussed, the more likely something concrete can come out of it."

The synchronous talker is useful in enabling greater focus on the more general topics posted on the discussion board. The synchronous discussion begins on a very broad topic and focuses on a particular practical, workable aspect of the topic. At the same time, some differences of opinion do emerge while ideas are being generated. This is illustrated in transcript 1, of an electronic ICGITD meeting.

$\boldsymbol{L}$ 'We have found in our INDIX meetings with other donor organizations at the bilateral level that government policy still severely limits information sharing and access between countries'

$\boldsymbol{R}$ 'I am sure governments are able to isolate information that can be put into the public domain as opposed to sensitive information. Transparency in the age of open governance should facilitate this.'

Transcript 1: Opinions and Open Discussion

In their study of computer conferencing, Hiltz and Turoff (1993) observe that there are always one or two individuals that dominate distributed synchronous meetings. The experience of the international agency network confirms this and suggests that the role of an 'effective chairperson in such an environment is not democratic but draws upon the more traditional functions of maintaining structure and focus through authority based upon position. This is illustrated in transcript 2 . The role of the chairperson is very explicit. There is no question about his command over the discussion, selection and time given for debate of the items on the agenda. Although all members do get a chance to air their views, experience suggests that it is the members with projects that are making clear progress that have the most to say. In addition, those members who just want to air their ideas without making any significant contribution to the discussion find themselves at the fringes of the discussion while the influential members get on with their own agenda. Influence in an electronic group meeting is not only associated with the activities that the participants are involved in but also the status of members in their own organisation; this bears considerable weight on their influence in the group discussions. In addition, the information that members have access to gives them an element of credibility in the general discussion. 
Chairman 'We were planning begin with a pilot database at the Commonwealth Secretariat and then transfer it to an institution in a user country such as Malta as its is a small country and it provides a window to developing and developed countries. But do you have other suggestions ?'

I 'If you have developed the data base it is absolutely essential to use it, to connect to it otherwise it is dead, useless and soon becomes inefficient'

$\boldsymbol{N}$ 'with the database, it seems to me that we need to think about 1 willingness to use it; 2 ability to use it; and 3 need to use it'

$\boldsymbol{R}$ 'a most practical mechanism would be to incorporate such information in a database that is widely or easily globally accessible by interested parties such as on the WWW'

Transcript 2: Chairing

It is worth noting that while the talker facilitates and enables a mechanism for consultation and collaboration, it could also be seen to bring out the views of people of the different institutions to each other. This is illustrated in transcript 3. This mechanism for consultation and collaboration involves a politically sensitive form of communication among a group of donor agencies who have until recently been unaccustomed to this use of the technology. This points towards certain implications for group support and how it may be made conducive to the network way of working.

$\boldsymbol{R}$ 'something like good government is very relevant and well defined and finds an audience easily.

$V$ 'OK. If one is to discuss IT in government, how about a specific issue like "Access to Government Information"?'

Chairperson 'Could you please suggest a more focused topic V, as you already have a DSS workshop.'

$\boldsymbol{R}$ 'we can get a few different groups in different cities of the world listen to a panel discussion and send in their own comments in real time'

$O$ 'or government information systems (gis).'

$\boldsymbol{R}$ 'access to govt information sounds very attractive we have lots of govt information, but not the access!' :

$V$ 'slightly different group than "government officials" although the government folk are the ultimate beneficiaries of all this technical work (plus of course the people THEY in turn service).'

Transcript 3: Different Views 
When supporting a group working as a network using electronic group communication technology, it is worth considering certain functionalities that may be built into the technology. At the same time, the social processes that govern interaction on the electronic media need to be considered in the light of communication etiquette, institutional and political sensitivities, and cultural considerations. In other words, the electronic social space must be sustained and strengthened in order to provide appropriate and effective support for a network way of working. In the following sections, results from the project are distilled into practical insights drawing upon structuration theory to guide the inquiry.

\subsection{Appropriation}

Structuration theory (Giddens 1984) provides valuable insight into such social processes. A particular application of structuration theory to computer mediated communication is offered by DeSanctis and Poole (1994). They propose a 'Theory of Adaptive Structuration' which states that as group members use GDSS to complete a task, they are developing and applying rules and resources for the conduct of behaviour. The rules and resources of the group direct members as to which features of the technology they should appropriate. They found that when individuals in a group interact using GDSS, each group produces and reproduces its own structures-in-use. This process, they claim, accounts for the continual changing nature of social structures involved in the use of group decision support systems. The Notice Board provided the ICGITD with very simple tools that participants could use to support their own ways of communicating.

At the same time, members of the network bring with them their own perceptions and cultural backgrounds when interacting on the electronic media. The result, is a curious amalgamation of these norms and perceptions. These manifest themselves on the communication media and can be seen to add to the ordeal of moderating a meeting. In effect, these social interactions that take place on the electronic media can be seen to create an electronic social space in which a set of norms and perspectives develop and become accepted within that group of people. The electronic social space creates within it a totally different way of communicating and brings forth sets of interactions that as yet have been non existent (Qureshi 1995b). This suggests that the technology has to be flexible enough to support changing work patterns and at the same time requires a design that is stable enough to merit use over a long period of time.

\subsection{Adaptation}

In view of supporting the fluid nature of interactions on the electronic social space, while at the same time providing the necessary tools to structure meetings, three types of adaptation need to be considered. The technology has to be appropriate with a sufficient set of tools from which users may choose to support their communication. The experience of this study suggests that the technology also has to be simple, and easy to use. Extensive windowing facilities intended to yield user-friendliness tend to hinder rather than facilitate use. The results of a related study, in which the same technology was used by a different group (Qureshi 1995b), suggest that groups go through processes of adapting to the electronic social space. These processes of adaptation to the technology, the work environment, and the emergent social processes are also identified in the study reported in this paper. These processes are considered in greater detail in Qureshi (1995a, 1995b) but for the purpose of this paper, the following sections focus on a consideration of adaptation among participants of the international agency network. 


\section{Technological adaptation}

In this study, technological adaptation entails learning how to use the technology and more importantly how to get around the numerous difficulties that it presents. The participants had to get accustomed to the environment of the software; in particular, how to use the basic commands, entertain themselves with the more amusing commands and then communicate with each other using these commands. An examination of the meeting transcripts suggests that this particular group of participants were relatively familiar with the technology and were comfortable enough with it to be able to discuss important and somewhat sensitive issues on the electronic social space. They did not use the additional 'rooms' available on the talker. However, the technology did have the potential of influencing the meetings as contributions were very much dependant upon the typing skills of the participants. In effect, the lack of turn yielding cues available in face to face communication meant that chairing the meetings was not straightforward. Tool support for chairing the meetings could enhance the electronic social space considerably.

\section{Work adaptation}

The electronic social space presented the ICGITD members with a work environment that was different from what they were accustomed to. These participants brought into the social space ways of working that are familiar to them in their own organisations (as would be the case in face to face meetings). When these varying perceptions and norms of behaviour come together on the electronic environment, new ways of working emerge. The study reported in this paper reveals a set of working relations that are inherently political. The lack of visual cues and subtle intonations on the electronic social space meant that the political meandering, common in the face to face meetings among these civil servants, was impeded. Thus the participants adapted to this new work environment by having more formal and, compared to the face to face meetings, more focused interaction. Supporting work adaptation, the process of getting accustomed to a work environment that takes place electronically, entails a dual relation between the behaviours of the participants and the ways of working that they are accustomed to. It is thus necessary to consider the rules and regulations, responsibilities of the users, their positions with respect to their colleagues and the importance (immediacy) of the tasks (Dawson 1986, Child 1988).

\section{Social adaptation}

The social process is perhaps the most important and least understood of the factors that influence interaction on the electronic social space. Values, norms and perceptions created over time in the minds of human actors are manifest in the way in which human actors behave on the electronic social space. Interaction among human actors also contributes to changing these values, norms and perceptions and thus behaviour. In view of this, supporting social adaptation is not quite as straightforward as one might expect, especially as it is most effective when social adaptation emerges when people learn more about their environment and are thus able to shape the social space to suit their own habits. In the study reported here, the technology tempered the ability of the participants to express their perceptions, norms and values, and the very subtle cultural nuances were brought to bear in different ways. Communication etiquette developed gradually and benefited from the participants who were more familiar with communicating electronically.

\section{CONCLUSIONS AND SUGGESTED FURTHER RESEARCH}

This paper describes the use of an electronic communication system supporting a network of international agencies. It follows an interpretive research strategy to obtain a rich in-depth description of how the 
network way of working, the network of international agencies (ICGITD), operates using the technology in a real life situation. From this description, issues arise relating to group support for structuring decisions and conducting meetings. It appears that structured discussions may be more appropriate for topics that require an exchange of information and ideas whereas synchronous communication has a more definite purpose as it allows a degree of social interaction. The paper suggests that the technology enables a network way of working, and in so doing must provide users with the tools to allow them to use the technology to suit their own ways of communicating. Further research investigating the leadership function, in particular the role of the chairperson, considering carefully the nature of the electronic social space may potentially provide further insight into appropriate and effective support for a network way of working.

\section{REFERENCES}

Argyris, C., R. Putnam and McLain Smith, D. (1982) Action Science - Concepts, Methods and Skills for Research and Intervention. Josey-Bass, San Francisco.

Charan, R. (1991) How Networks Reshape Organisations for Results . Harvard Business Review. 91503, 104-115.

Child, J. (1988) Organisation: A Guide To Practice and Problems. Harper and Row, London.

Dawson, S. (1986) Analyzing Organisations. Macmillan, London.

Dennis, A.R.J.F., L.M. George, L.M. Jessup, J.F. Nunamaker and Vogel, D.R. (1988) Information Technology to Support Electronic Meetings . MIS Quarterly. 12(4), 591-624.

DeSanctis, G. and Gallupe, R.B. (1987) A Foundation for the Study of Group Decision Support Systems . Management Science. 33(5), 589-609.

DeSanctis, G. and Poole, M.S. (1994) Capturing the Complexity in Advanced Technology Use: Adaptive Structuration Theory. Organization Science. 5(2), 121-147.

Drucker, P. (1988) The Coming of the New Organisation. Harvard Business Review. January-February.

Giddens, A. (1984) The Constitution of Society. Polity, Cambridge.

Hiltz, S.R. and Turoff, M. (1992) Virtual Meetings: Computer Conferencing and Distributed Group Support. in Computer Augmented Teamwork (ed. R.P. Bostrom, R.T. Watson and S. Kinney), Van Nostrand Reinhold, New York.

Hiltz, R.S. and M. Turoff. (1993) The Network Nation, Human Communication via Computer. Addison-Wesley, London.

Kanter, R.M. (1983) The Change Masters. Unwin, New York.

Keisler, S., J. Seigal and McGuire, T. (1987) Information Technology Social Issues: A Reader. Hodder \& Stoughton, London.

McCall, G.J. and Simmons, J.L. (1969) Issues in Participant Observation: A Text and a Reader. Random House, New York.

Nunamaker, J.F., L.M. Applegate and Konsysnski, B.R. (1988) Computer-aided Deliberation: Model management and Group Decision Support. Operations Research, Special Issue on Decision Support Systems. 36(6), 826-848.

Perin, C. (1991) Electronic Social Fields in Bureaucracies. Communications of the ACM. 34(12), 75-82.

Qureshi, S., (1995a) Supporting Electronic Group Processes: a social perspective. in Supporting Teams, Groups, and Learning Inside and Outside the IS Function (ed. L. Olfman), SIGCPR/ACM, Nashville. 
Qureshi, S., (1995b) Organisations and Networks: Theoretical Considerations and a Case Study, $\mathrm{PhD}$ Thesis, London School of Economics.

Sproull, L. and S. Kiesler. (1991) Computers, Networks and Work. Scientific American. 265(3), 84-91.

\section{BIOGRAPHY}

Dr Sajda Qureshi is a research fellow at the Erasmus University Research Institute for Decision and Information Systems (EURIDIS) and a visiting assistant professor at the Rotterdam School of Management at Erasmus University Rotterdam, in the Netherlands. She has been Coordinator of the Commonwealth Network of Information Technology for Development (COMNET-IT) at the Commonwealth Secretariat in London, the UK. She has also been employed at the London School of Economics as a research assistant developing an organisational modelling system as part of an EEC project. She has research and consultancy experience in developing information systems in Italy and the UK. 